\title{
Issues related to Health Promotional measures at workplace
}

\author{
Ganesh Kumar S
}

Department of Preventive and Social Medicine, JPMER, Puducherry, India

Health promotional measures at workplace are still an ignored issue especially in developing countries. Occupational Health, as defined by a joint committee of World Health Organization and the International Labour Organization, involves the promotion and maintenance of the highest degree of physical, mental and social well-being of workers in all occupations. Occupational Health Practitioners have long recognized health promotion to be an integral part of a comprehensive occupational health care system. The World Health Organization (WHO) estimated in 2007 that the global labour force was half of the world's population (1).

Workers are exposed to various physical, chemical, biological, mechanical and psychosocial hazards depending on the work involved and the place of the work. Assessment of risk of work and distribution of workforce into the various sectors is the first step towards attaining health promotional measures. The purpose of risk assessment is to ensure that a valid decision can be made for measures necessary to control exposure to substances hazardous to health arising in workplace. Expertise, effort, and details required in risk assessment depends on the nature and degree of risk, and the complexity of the work process. Adequate control measures are determined based on several factors, such as the toxicity of the substance, numbers exposed, acceptability of risk, legal requirements, costs, and availability of control measures1. Risk will be related to host factors like age, sex, job duration, time of the work in the day, presence of any addictions. Risk level and distribution of workforce varies from country to country. In developing countries like India, agricultural sector where more than half of the total work force is employed is a point of concern. Besides, majority of the workers are coming under unorganized sector and data are not available pertinent to various types of hazards and risks. They are more prone to accidents, toxic and physical hazards, zoonotic and respiratory -

(c) 2011 OHSSN All rights reserved. diseases. The prevalence rate of accidents ranges from $7.8 \%$ to $27.7 \%$ depending upon the type of work performed (2). Prevalence work related injuries is $35 \%$ among all injuries reported in a public sector industry (3). Another study highlighted that prevalence of accidents in tile factories as $18.5 \%$ (4). It has shown that young and less experienced workers are more prone to accidents.

Recognition of vulnerable populations in developing countries that includes child labour, migrant population, women works, and disabled population is the second step of health promotional concept. They are suffered more adverse effects due to non availability of services. Besides they are more prone to get various types of communicable and non communicable diseases. Due importance should be given through legal, educational and community based approach to these vulnerable population.

Elimination of the hazard or substitution with a safer alternative, engineering controls, redesign of the work station or process, health education of workers, safer work practices, use of personal protective equipments, good personal hygiene practices, safe water supply and sanitation of the work place, pre placement examination, promotion of mental health through recreational activities, good housing conditions, health and other benefits to vulnerable groups are some of the health promotional measures required for the workers. But, in many developing countries there is no comprehensive occupational health services existing towards these aspects. However there are various organizations active in the field of occupational health.

Administrative control is one of the important measures to reduce worker exposure to occupational hazards. This could take the form of job enlargement or job rotation, restrictions of hours of work at a hazardous operation, or temporary job reassignment. With this measure duration of exposure to hazardous substances will be reduced. Simultaneously workers should be 
educated regarding recognition of work hazards, safe work environment, disaster management techniques, handling of emergency situations and prevention of communicable, non communicable diseases. Research should be strengthened in all these areas to assess this important problem and remedial measures. Political commitment for legal approach with the implementation of health promotional measures towards achieving the safety of the workers is an important task in this regard.

References:

1. David Koh, Dean Baker. Occupational Health in Oxford Textbook of Public health, $5^{\text {th }}$ edition, Oxford University Press 2009.

2. Nag PK, Nag A. Drudgery, accidents and injuries in Indian Agriculture. Ind Health 2004;42:149-62.

3. Sarma BP. Epidemiology and man days loss in burn injuries amongst workers in an oil industry. Burns 2001;27:475-80.

4. Ganesh Kumar S, Rathnakar UP, Harsha Kumar HN. Epidemiology of accidents in tile factories of Mangalore city in Karnataka. Indian J Community Med 2010;35:78-81 